\title{
Effect of Short Term Aging on Unmodified and Local Crumb Rubber (LCR) Modified Bitumen
}

\author{
Muhammad Saad Waheed ${ }^{1, *}$, Manzoor Elahi ${ }^{2}$ \\ ${ }^{1}$ Department of Civil Engineering Technology, City University of Science and Information Technology, Peshawar, Pakistan. \\ ${ }^{2}$ Department of Civil Engineering, University of Engineering and Technology, Peshawar, Pakistan. \\ ${ }^{*}$ Corresponding author: saadmwaheed@gmail.com
}

Abstract

Two grades of bitumen, (60/70 and 80/100), were modified by addition of Local Crumb Rubber (LCR) by weight of base bitumen. To investigate the effects of short-term aging on modified and LCR modified bitumen, Rolling Thin Film Oven (RTFO) test was used to simulate the short term aging. Dynamic shear rheometer (DSR) was used to assess the rheological properties of bitumen, both before and after aging. It was observed that at $65^{\circ} \mathrm{C}$ on aging, the phase angle $(\delta)$ of unmodified bitumen decreased by 3 and $4 \%$ for $60 / 70$ and $80 / 100$ bitumen respectively; whereas, for $60 / 70$ LCR modified bitumen, the phase angle $(\delta)$ on RTFO aging decreased by $7 \%$ for all LCR content $(10$, 15 and $20 \%$ ) by weight of base bitumen. However, on RTFO aging $(\delta)$, values for LCR modified 80/100 bitumen varied across different LCR content and could not be generalized. The complex modulus $\left|G^{*}\right|$ of LCR modified $60 / 70$ bitumen increased on aging for both modified and unmodified bitumen at $65^{\circ} \mathrm{C}$, but with the increase in LCR content, the difference between bitumen aged and un-aged values of $\left|\mathrm{G}^{*}\right|$ was considerably lowered. An interesting finding was for $80 / 100$ bitumen modified with $20 \%$ LCR content by weight, which showed a reduction in $\left|G^{*}\right|$ values and an increase in $(\delta)$ values on aging. This shows that to some extent, LCR compensates for the stiffening effects of aging.

Keywords-Rolling Thing Film Oven (RTFO), Dynamic Shear Rheometer (DSR), Local Crumb Rubber (LCR), Aging, Bitumen

\section{Introduction}

$\mathrm{C}$ RUMB Rubber (CR) from end of life tyres is used to improve the engineering properties of bitumen. Two types of processes, namely, wet process and dry process are currently being used to modify the properties of bitumen. Wet process involves mixing bitumen with $\mathrm{CR}$ at elevated temperature prior to its mixing with aggregates, whereas, in dry process the $\mathrm{CR}$ is mixed with heated aggregates before addition of bitumen. [1][2]. Bitumen consists of two broad fractions: the lighter fractions called the maltenes, and heavier fractions called the asphaltenes. During bitumen$\mathrm{CR}$ interaction, the $\mathrm{CR}$ particles absorb the lighter fractions of bitumen and swell [3]. Thus CR modified bitumen consists of a liquid phase and swollen particle phase. The modification of bitumen generally occurs

ISSN: 2523-0379 (Online), ISSN: 1605-8607 (Print)

DOI: 10.52584/QRJ.1802.10

This is an open access article published by Quaid-e-Awam University of Engineering Science \& Technology, Nawabshah, Pakistan under CC BY 4.0 International License. due to migration of lighter fractions from bitumen into CR particles. This leads to a reduction of lighter fractions of bitumen and results in an increase in complex modulus $\left|\mathrm{G}^{*}\right|$ values and a reduction in phase angle $(\delta)$ values [4][5]. Factors affecting the properties of CR modified binder include time and temperature of bitumen - CR interaction, CR particle size, shape and content [6][7]. The reaction between $\mathrm{CR}$ and bitumen is highly dependent on time and temperature. If any of these two parameters are in excess, the rubber particles will go into a de-polymerization phase and beneficial effects of modification will be lost [4]. According to Mashan et. al., the properties of CR modified bitumen are directly affected by the quantity of CR modifier [7]. With respect to size and shape of CR particles, various researchers have shown that increasing the size of crumb rubber particles results in decrease in $(\delta)$ values and an increase in $\left|\mathrm{G}^{*}\right|$ values. Thus, CR modified bitumen produced from coarser particles tend to have better elastic properties due to 


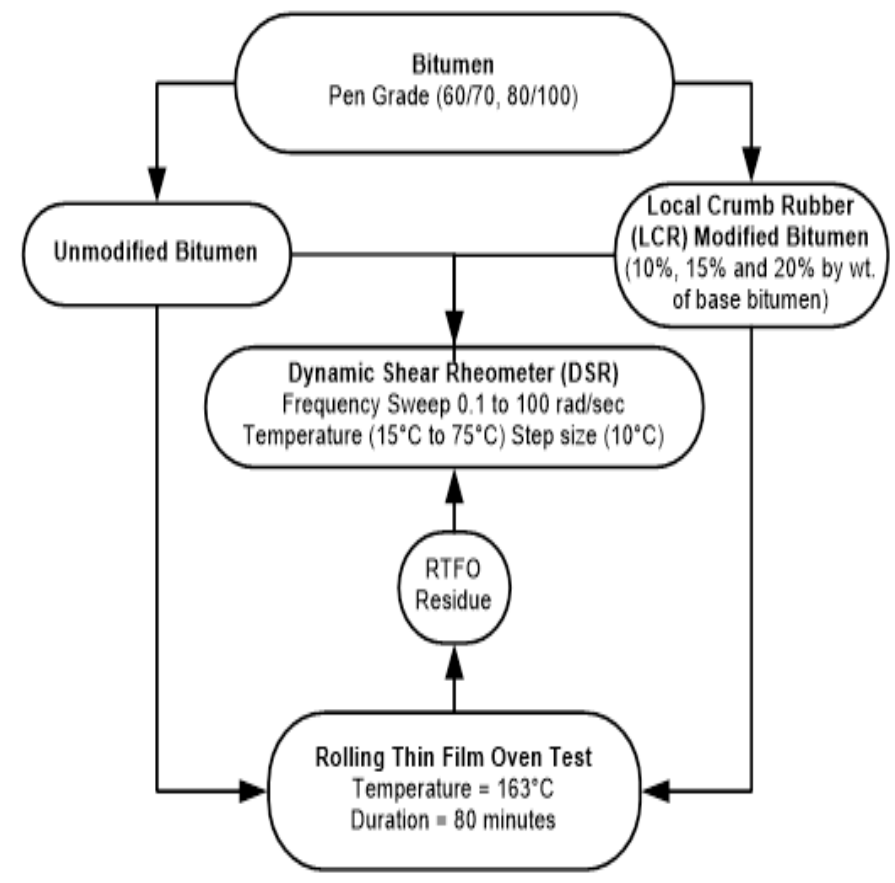

Fig. 1: The methodology adopted in the research

lower value of $(\delta)$ and high rutting resistance due to higher $\left|G^{*}\right|$ values [8].

In general, bitumen undergoes two types of aging: (i) short-term aging that occurs during the initial asphalt production and laying, (ii) and a long term aging that continues throughout the service life of the pavement and is the result of environmental factors [9][10]. Main types of aging processes that are considered when studying the aging of bitumen include oxidation, evaporation of lighter fractions, absorption of bitumen fractions by aggregates, and physical hardening, also known as steric hardening. Oxidation is considered to be the main cause of aging and results in the changes in chemical structure of bitumen [9]. The changes in chemical structure result from increase in asphaltenes contents and their molecular weight, and is accompanied by decrease in the maltenes (aromatic oils) [11][12]. The chemical changes are mostly the result of combination of processes that involve oxidation, polymerization and evaporation of lighter fractions. This leads to hardening of the binder, and makes it more susceptible to cracking failures [12].

Aging of bitumen modified with crumb rubber is a complex phenomenon, since aging of crumb rubber modified bitumen is affected by both oxidation process and polymer degradation [10]. According to Lesueur [12], short term aging that occurs at the temperature of $160^{\circ} \mathrm{C}$, shows good correlation with aging using the rolling thing film vven test. This study focuses on short-term aging of bitumen and its effects on bitumen properties, since before the asphalt mix reaches the site, considerable aging has taken place during mixing process that affects the in situ performance of bitumen. The CR that is being used for modification of bitumen is obtained from two distinct industrial processes: ambient and cryogenic. The local crumb rubber (LCR) that is used in this research is obtained from neither of the two processes, but is a waste product generated from local shoe industry during grinding of shoe soles which are made up of waste rubber products such as end of life tyres, conveyor belts, etc. In this research, two grades of bitumen 60/70 and 80/100 are modified with LCR using the wet process. This study demonstrates the usefulness of LCR as a modifier for bitumen.

\section{Material \& Methods}

Local Crumb Rubber (LCR) used for this research was obtained from local shoe makers, where it is generated as a result of utilization of waste rubber products such as end of life tyres, conveyor belts, etc. in shoe making and is dumped as a waste product. LCR passing sieve\# 30 having following gradation (Table 1) was used in this research as bitumen modifier. Two grades of bitumen (pen grade 60/70 and 80/100) were used as base bitumen. LCR was mixed with based bitumen at a temperature of $180^{\circ} \mathrm{C}$. Mixing was carried out in a laboratory asphalt mixer for 30 minutes at a speed of $1400 \mathrm{rpm}$. Glass jars filled with binder were placed in RTFO apparatus to simulate short-term aging. The temperature was kept at $163^{\circ} \mathrm{C}$ and test duration was set to 80 minutes in accordance with AASHTO - T240 [13]. On un-aged and the residue from RTFO test, frequency sweep was run from (0.1 to 100) rad $/ \mathrm{sec}$ using DSR for temperature range $15^{\circ} \mathrm{C}, 25^{\circ} \mathrm{C}, 35^{\circ} \mathrm{C}$, $45^{\circ} \mathrm{C}, 55^{\circ} \mathrm{C}, 65^{\circ} \mathrm{C}$ and $75^{\circ} \mathrm{C}$. Dynamic Shear Rheometer (DSR) test assembly used was $25 \mathrm{~mm}$ plate with 1 mm plate gap.

\begin{tabular}{ccccc}
\hline Sieve Number & $\# 30$ & $\# 50$ & $\# 100$ & $\# 200$ \\
\hline Percent Passing & 100 & 49.1 & 12.87 & 4.19 \\
\hline
\end{tabular}

TABLE 1: LCR gradation

\section{Results \& Discussion}

Following sections describe the results of this study.

\subsection{Rolling Thin Film Oven (RTFO) Test}

The result of mass loss percentage after RTFO aging is given below. The results indicate that the LCR 


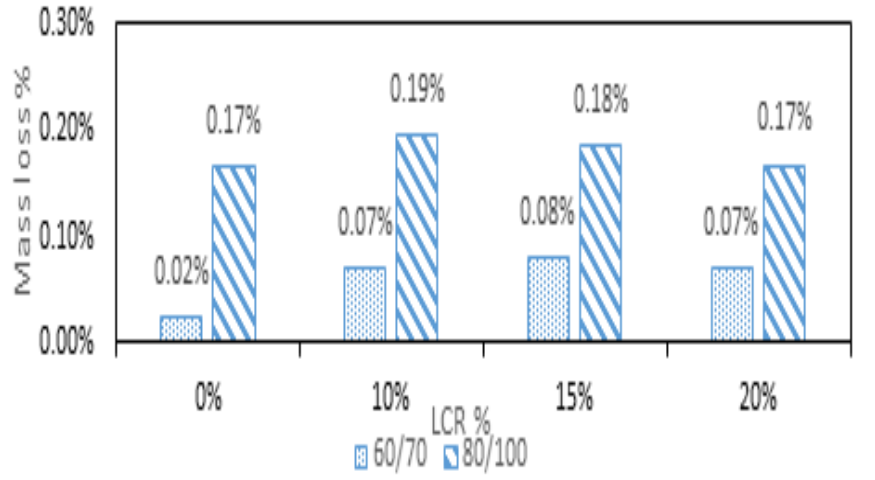

Fig. 2: RTFO mass Loss percentage

modified bitumen has higher mass loss percentage than the unmodified bitumen. As the LCR content is increased, the mass loss percentage increases up to a maximum value of $0.08 \%$ at $15 \%$ LCR content by weight of base bitumen for $60 / 70$ bitumen. On further increase in the LCR content, the mass loss percentage reduces to $0.07 \%$ which is still comparatively higher than the unmodified bitumen. For 80/100 bitumen, the mass loss percentage increases to a maximum value of $0.19 \%$ at $10 \%$ LCR content after which it begins to reduce on further increase in the LCR content.

\subsection{Isochronal Plot}

The phase angle $(\delta)$ isochronal plots for $60 / 70$ and $80 / 100$ bitumen are given below. It can be observed that addition of LCR results in decrease in the $(\delta)$ values at high temperature. The $(\delta)$ continues to decrease with the increase in LCR content. This finding is similar to that of conventional crumb rubber modified bitumen [7][4][8].This indicates that the increase in LCR content results in a decrease in the viscous component of bitumen. From Figure 3 and 4, it can be seen that with the increase in temperature, the $(\delta)$ value approaches $90^{\circ} \mathrm{C}$ which indicates that the material is approaching a viscous state [14]. It can be observed that on aging, the phase angle values reduces, indicating a loss of viscous component of bitumen. The difference between $(\delta)$ values is more evident at temperature greater than $45^{\circ} \mathrm{C}$. Furthermore, at temperature less than $20^{\circ} \mathrm{C}$, the LCR modifier bitumen has higher $\delta$ values. As the temperature increases, the graph plummets and then steadily rises. This behaviour is similar for both RTFO-aged and un-aged samples, and can be attributed to the particle effect of LCR and DSR plate geometry [15][16]. Both grades of bitumen $60 / 70$ and $80 / 100$ show the same behaviour for phase angle parameter at $10 \mathrm{rad} / \mathrm{sec}$.
Comparison of aged and un-aged bitumen for modified and unmodified bitumen is given below in the bar charts to further quantify the effects of aging on bitumen. It can be observed that for $60 / 70$ bitumen, aging increases the value of $(\delta)$ at low temperature of $15^{\circ} \mathrm{C}$, whereas at a high temperature of $65^{\circ} \mathrm{C}$, it results in the decreases in $(\delta)$ values. At temperature of $15^{\circ} \mathrm{C}$, the value of $(\delta)$ increases by $3 \%$ on aging unmodified bitumen, and increased by $10 \%, 9 \%$ and $27 \%$ for 10,15 and $20 \%$ LCR content respectively by weight of base bitumen. At temperature of $65^{\circ} \mathrm{C}$, the value decreased by $3 \%$ for unmodified bitumen and decreased by $7 \%$ for all quantities of LCR content. 80/100 bitumen showed varying response. At low temperature, the $(\delta)$ increased by $15 \%$ on aging for unmodified bitumen, and increased by $10 \%$ and $20 \%$ for $10 \%$ and $15 \%$ LCR content respectively by weight of base bitumen. The smallest increase of $5 \%$ in $(\delta)$ value was observed for $20 \%$ LCR content. At high temperature of $65^{\circ} \mathrm{C},(\delta)$ decreased by $4 \%$ and $1 \%$ for unmodified bitumen and for $15 \%$ LCR content, respectively. Whereas, for $10 \%$ and $20 \%$ LCR content, there is an increase in the $(\delta)$ value.

From figure 9 and 10, after aging using RTFO, the values of complex modulus $\left|G^{*}\right|$ increased. The increase in the values of $\left|G^{*}\right|$ was evident both at high and low temperature, except for the RTFO aged $60 / 70$ bitumen as the temperature is reduced. Its $\left|\mathrm{G}^{*}\right|$ value also reduces and from the temperature range of $25^{\circ} \mathrm{C}$ begins to fall behind un-aged $60 / 70$ bitumen. The trend of increase in $\left|G^{*}\right|$ values is similar for all LCR modified samples.

To further quantify the response of bitumen, at the high and low temperature range, the bar charts of $\left|\mathrm{G}^{*}\right|$ of bitumen sample at $65^{\circ} \mathrm{C}$ and $15^{\circ} \mathrm{C}$ are given below in Figure 11-14. It can be observed that for $60 / 70$ bitumen RTFO, aging results in an increase in the $\left|\mathrm{G}^{*}\right|$ value for both $65^{\circ} \mathrm{C}$ and $15^{\circ} \mathrm{C}$ except for unmodified bitumen at $15^{\circ} \mathrm{C}$, where there is a slight reduction in the $\left|\mathrm{G}^{*}\right|$ values from $257 \mathrm{KPa}$ to $249 \mathrm{KPa}$. On RTFO aging, both modified and unmodified bitumen showed an increase in the $\left|\mathrm{G}^{*}\right|$ at $65^{\circ} \mathrm{C}$, however, the extent of increase was limited to the increase in LCR content, as value of $\left|G^{*}\right|$ for unmodified bitumen increases by $102 \%$ on RTFO aging. Whereas, for $10 \%, 15 \%$ and $20 \%$ LCR content, it only increases by $35 \%, 29 \%$ and $17 \%$ respectively. This shows that, to some extent, LCR reduces the stiffness of bitumen. For 80/100 bitumen, the effects of RTFO aging vary across different LCR content at both $65^{\circ} \mathrm{C}$ and $15^{\circ} \mathrm{C}$. At $15^{\circ} \mathrm{C}$, an increase in the value of $\left|\mathrm{G}^{*}\right|$ is observed with the increase in LCR content. The RTFO aged 80/100 bitumen attain the maximum value of $350 \mathrm{KPa}$ at $15 \% \mathrm{LCR}$ content 

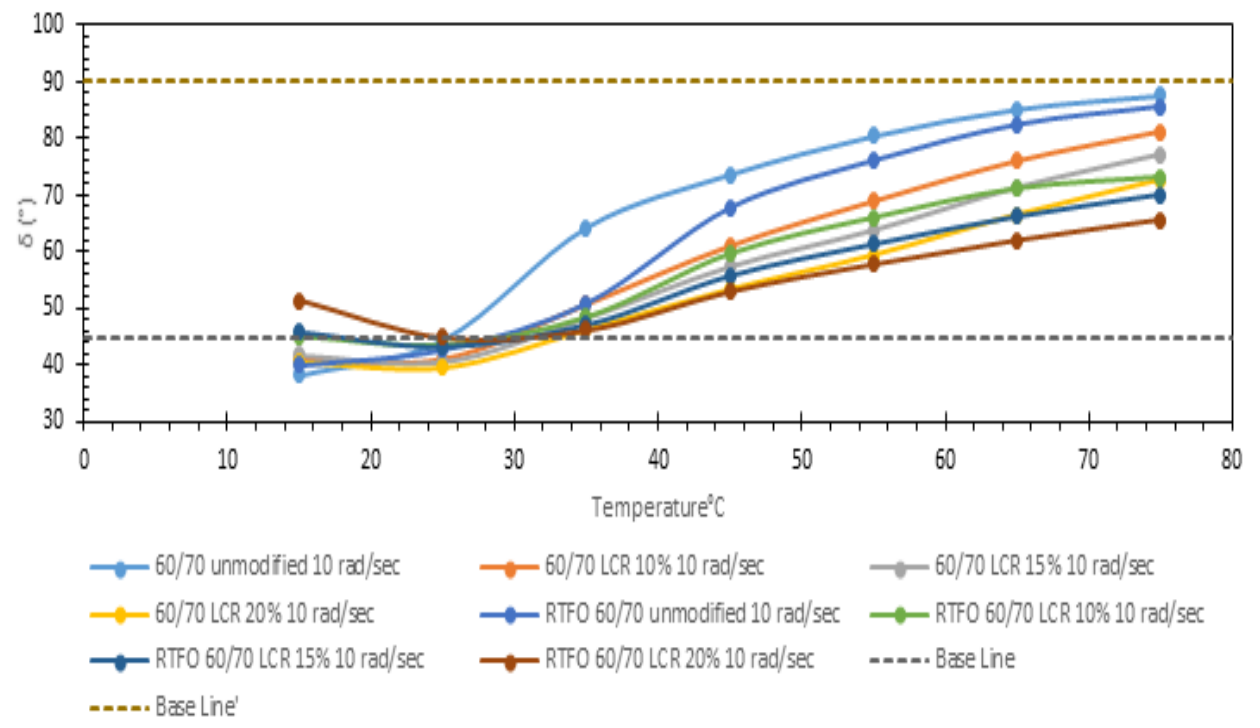

Fig. 3: Phase angle $(\delta)$ isochronal plot $60 / 70$ bitumen

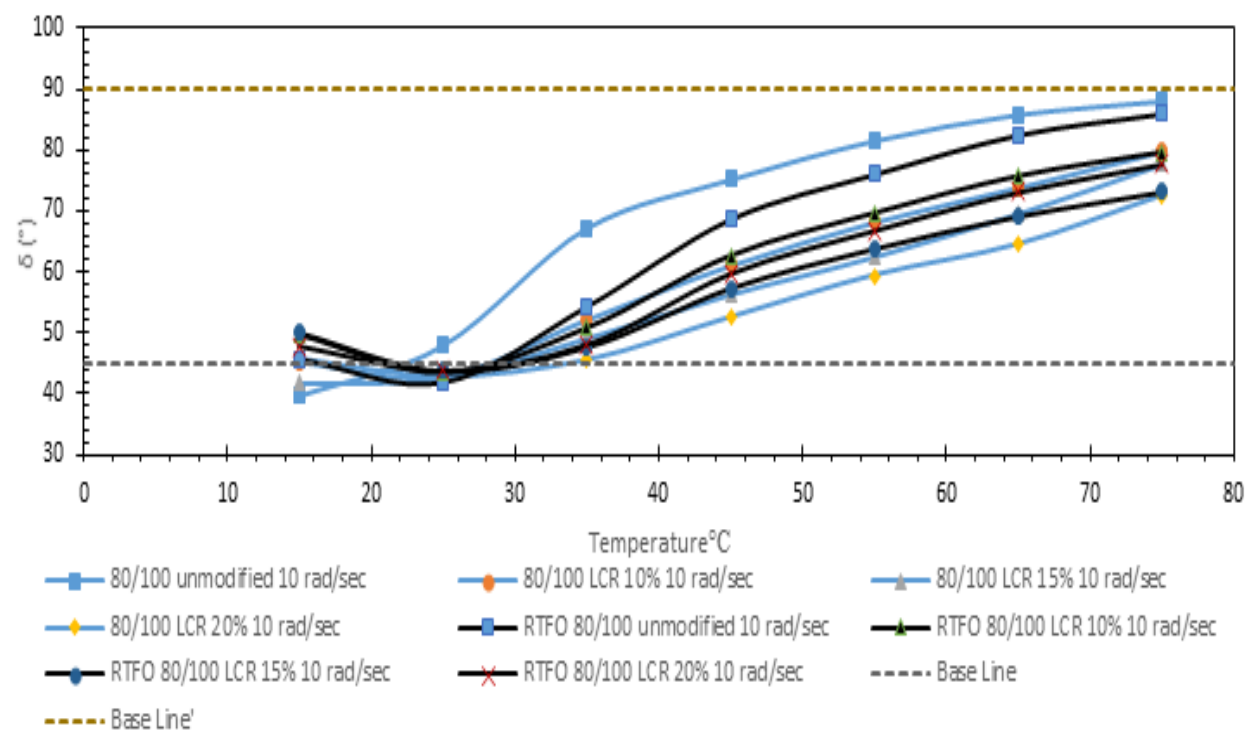

Fig. 4: Phase angle $(\delta)$ isochronal plot 80/100 bitumen

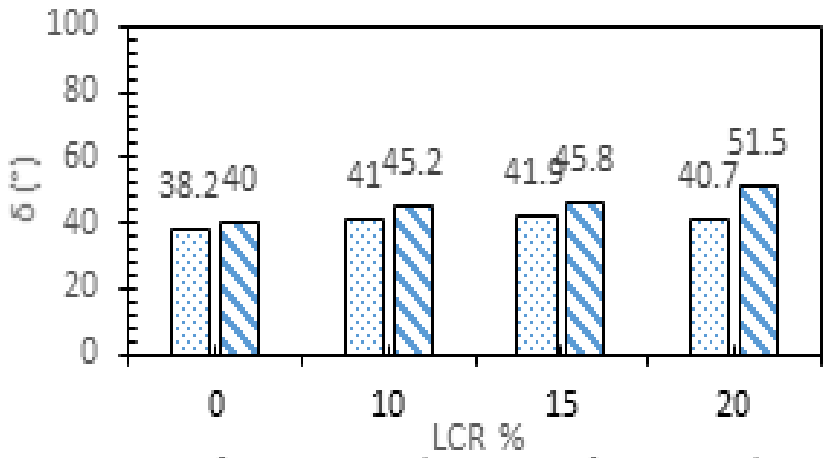

घ $815^{\circ} \mathrm{C}$ Unaged $60 / 70$ a $85^{\circ} \mathrm{C}$ RTF0 $60 / 70$

Fig. 5: Phase angle at $15^{\circ} \mathrm{C}$

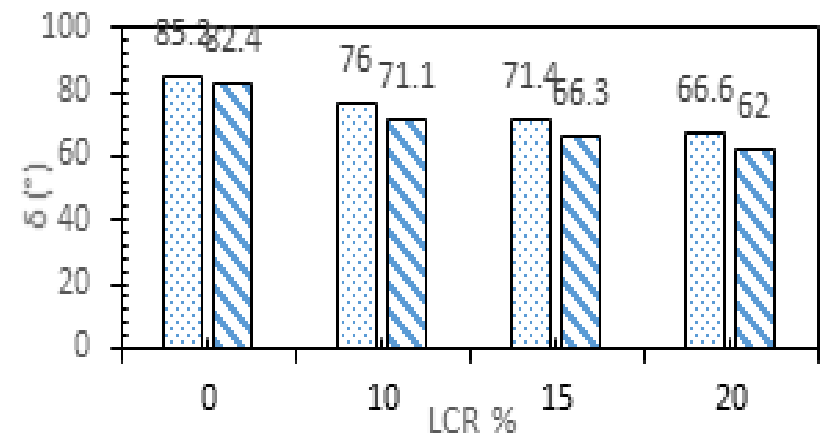

$\square 565^{\circ} \mathrm{C}$ Unaged $60 / 70 \quad \square 565^{\circ} \mathrm{C}$ RTF0 60/70

Fig. 6: Phase angle at $65^{\circ} \mathrm{C}$ 


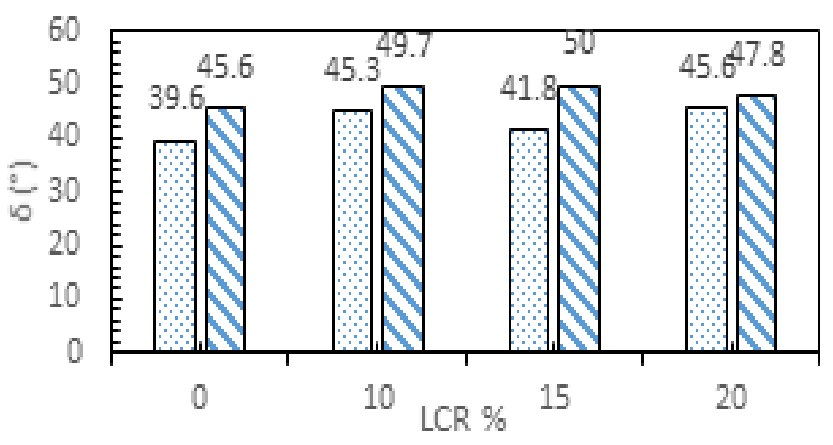

Q8 $15^{\circ} \mathrm{C}$ Unaged $80 / 100 \quad$ Q $015^{\circ} \mathrm{C}$ RTFO 80/100

Fig. 7: Phase angle at $15^{\circ} \mathrm{C}$

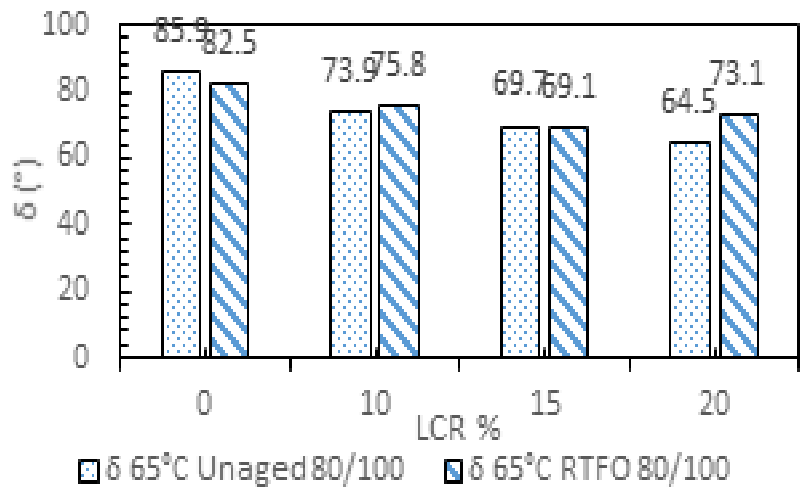

Fig. 8: Phase angle at $65^{\circ} \mathrm{C}$

at $15^{\circ} \mathrm{C}$. At $65^{\circ} \mathrm{C}, 80 / 100$ bitumen show unique behaviour for each LCR content. The value of $\left|G^{*}\right|$ increase from $0.85 \mathrm{KPa}$ to $2.09 \mathrm{KPa}$, and from $7.82 \mathrm{KPa}$ to $8.68 \mathrm{KPa}$ for $0 \%$ and $15 \% \mathrm{LCR}$ content respectively. It reduces from $5.79 \mathrm{KPa}$ to $3.63 \mathrm{KPa}$ and $8.27 \mathrm{KPa}$ to $4.87 \mathrm{KPa}$ for $10 \%$ and $20 \%$ LCR content. According to Haopeng et. al. [17], during aging, oxidation and polymer degradation for polymer modified bitumen occur simultaneously. Due to this reason, the stiffening effect of oxidation to some extent are compensated by the softening effect of polymer degradation. However, inconsistencies do exist in the values of $\left|\mathrm{G}^{*}\right|$ and $(\delta)$, therefore, it is not possible to completely characterize the aging phenomenon based on the selected values. Furthermore, the lowering of $(\delta)$ values and increase in $\left|\mathrm{G}^{*}\right|$ is visible at high temperature than at low temperature. Studies attribute this phenomena to the increased CR contribution to the bitumen rheology at high temperature as compared to low temperature [18].

\subsection{Master Curves}

For $60 / 70$ bitumen, the $(\delta)$ master curves fall to lower $(\delta)$ values on aging, which is consistent for both mod- ified and unmodified bitumen; however, at low temperature, considerable overlapping is observed between RTFO aged, modified and unmodified bitumen. Some scattering of the graph is also observed for RTFO-aged $20 \%$ LCR modified bitumen. A plateau is observed in the low frequency region (high temperature) for LCR modified bitumen, from where the value of the $(\delta)$ begins to fall below the curve in the $(\delta)$ master curve. The curvature of the curve at this low frequency region increases on both RTFO aging and on increasing LCR content. For $80 / 100$ bitumen, some scattering of $(\delta)$ values is observed in the high frequency region, but it was lower than the $60 / 70$ bitumen. Interestingly, RTFO-aged 80/100 bitumen modified with 15\% LCR gives the lowest values of $(\delta)$ in the low frequency region. Its curvature is also visibly the highest. Another interesting thing is the behaviour of RTFO-aged $20 \%$ LCR modified bitumen, which is characterised by overlapping with RTFO-aged $10 \%$ LCR modified bitumen both at high and low frequency region.

For $60 / 70$ bitumen, the values of $\left|G^{*}\right|$ increase both on aging and with the increase in LCR content. The effect of LCR addition and aging are more distinguishable in the frequency range $1 . \mathrm{E}-06 \mathrm{rad} / \mathrm{sec}-1$.E$01 \mathrm{rad} / \mathrm{sec}$. The un-aged samples show increase in the $\left|G^{*}\right|$ values on addition of LCR. The stiffening effect of LCR continue to increase with the increase in LCR content, as evident from the increase in $\left|G^{*}\right|$ value. For un-aged sample, the general behaviour remains the same with the LCR modified samples showing higher $\left|\mathrm{G}^{*}\right|$ values. For the case of 80/100 bitumen, RTFOaged LCR $20 \%$ values overlap with RTFO-aged LCR $10 \%$. The values of RTFO-aged LCR $20 \%$ was also lower than the un-aged LCR $20 \%$ values, which shows that some form of softening effect of LCR modification is present to balance the stiffening effect of aging. According to Haopeng et. al. [17], bitumen modified with higher percentage of crumb rubber shows better resistance against stiffening effects of aging. The difference in response between $60 / 70$ and $80 / 100$ bitumen can be attributed to the difference in grades of bitumen, as softer grade bitumen are known to enhance the swelling of crumb rubber particles due to the presence of greater amount of light-weight fractions. This results in better high and low temperature performance of modified binder [19].

\section{Conclusion}

From the results it can be concluded that:

- Addition of LCR reduces $(\delta)$ value of bitumen. The effect of $(\delta)$ modification is more visible at high temperature than at low temperature.. The 


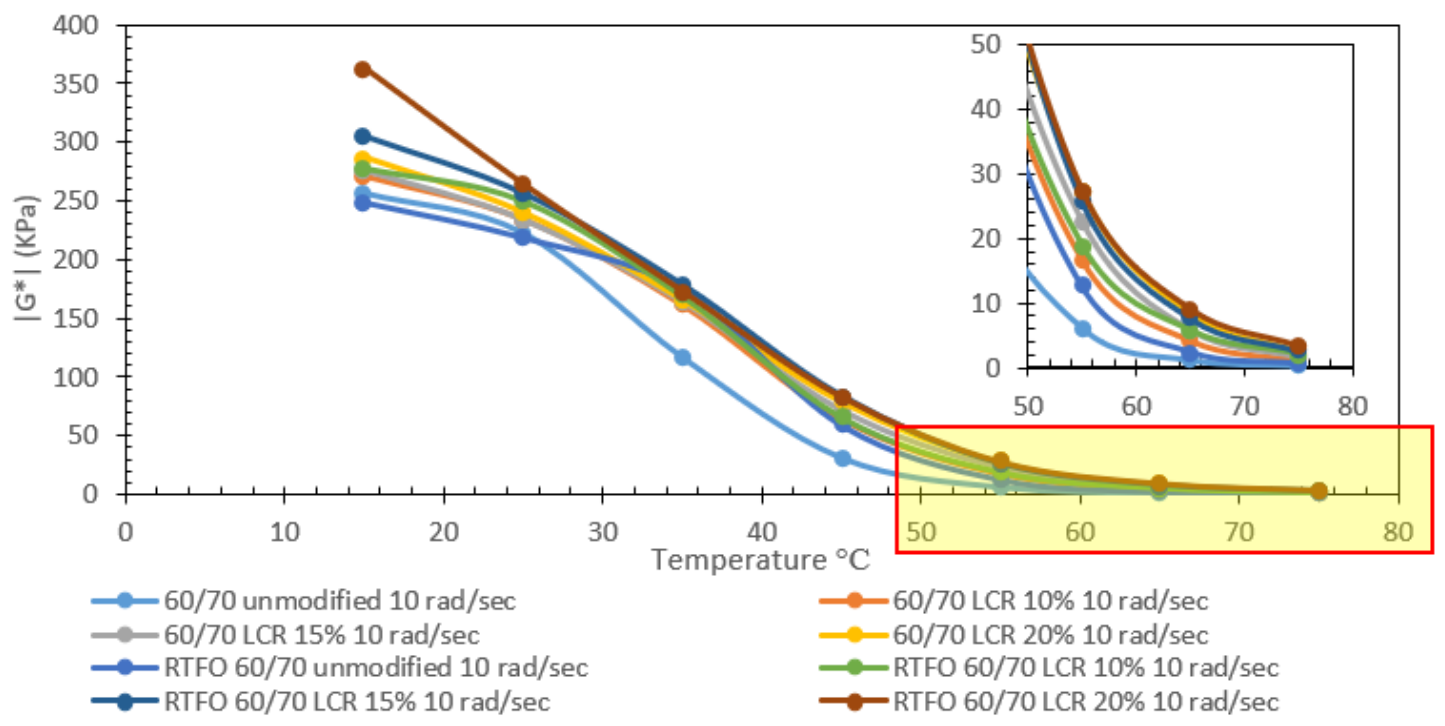

Fig. 9: Complex modulus, isochronal plot

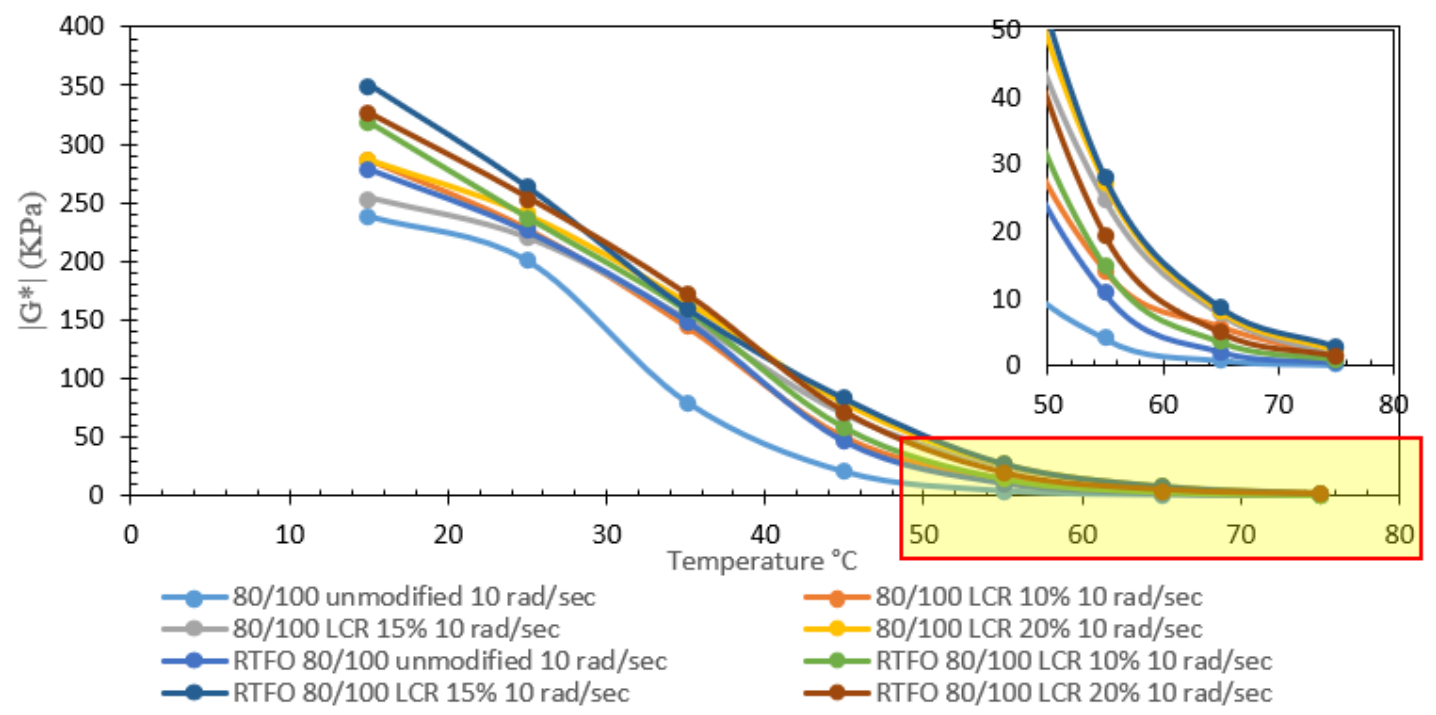

Fig. 10: Complex modulus, isochronal plot

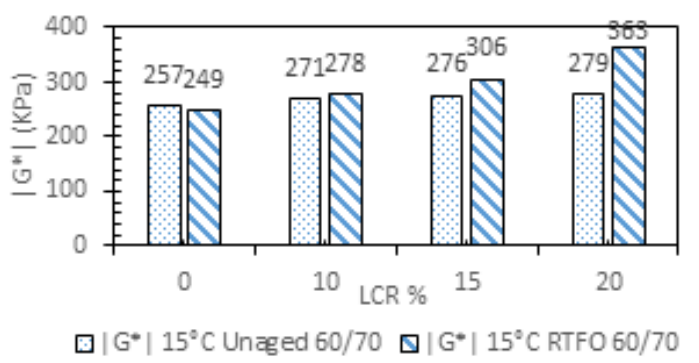

Fig. 11: Complex modulus at $15^{\circ} \mathrm{C}$

reduction in $(\delta)$ value of bitumen indicates a shift towards a more elastic response. This observation indicates that LCR can be used to improve the

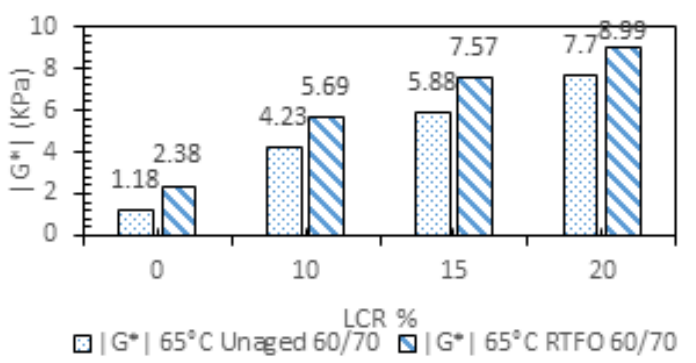

Fig. 12: Complex modulus at $65^{\circ} \mathrm{C}$

high temperature performance of bitumen. The modification of $(\delta)$ on addition of LCR is similar to that of conventional crumb rubber as observed 


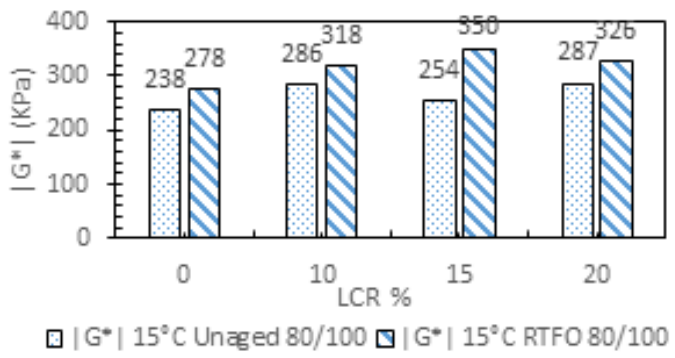

Fig. 13: Complex modulus at $15^{\circ} \mathrm{C}$

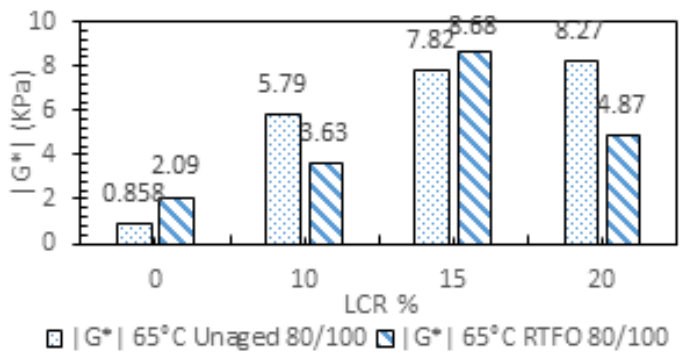

Fig. 14: Complex modulus at $65^{\circ} \mathrm{C}$

by other researchers.

- RTFO aging results show an increase in $\left|G^{*}\right|$ and a decrease in $(\delta)$ values for both grades $(60 / 70$ and $80 / 100)$ of unmodified bitumen. Similar result is obtained for 60/70 LCR modified bitumen. This shows that aging results in a more stiff and less viscous bitumen.

- For LCR modified 80/100 bitumen, the effects of RTFO aging vary for different LCR content. It is observed that for $20 \%$ LCR modified bitumen, there is a decrease in stiffness and $\left|G^{*}\right|$ values, but an increase in viscous component and $(\delta)$ values. This shows that the characteristics of base bitumen have a considerable effect on the properties of RTFO-aged LCR-modified bitumen. The increased LCR content for softer grade bitumen results in better aging resistance.

- To generalize these findings, further studies are needed with different bitumen sources and grades.

\section{References}

[1] N. S. Mashaan, A. H. Ali, M. R. Karim and M. Abdelaziz, "An overview of crumb rubber modified asphalt," International Journal of the Physical Sciences, vol. 7, no. 2, pp. 166-170, 2012.

[2] A. S. Eltwati, I. Saad and A. Elsaiti, "The Effect of Crumb Rubber on Properties of Asphalt Mix by Dry Process," International Journal of Engineering and Information Technology (IJEIT), vol. 5, no. 1, 2018.

[3] G. D. Airey, M. M. Rahman and A. C. Collop, "Absorption of Bitumen into Crumb Rubber Using the Basket Drainage Method," The International Journal of Pavement Engineering, vol. 4, no. 2, pp. 105-119, 2003.
[4] D. L. Presti, G. Aireya and P. Partal, "Manufacturing terminal and field bitumen-tyre rubber blends: the importance of processing conditions," in SIIV - 5th International Congress - Sustainability of Road Infrastructures, 2012.

[5] M. A. Abdel Rehman and S. H. Carpenter, "Mechanism of Interaction of Asphalt Cement with Crumb Rubber Modifier," Transportation Research Record 1661, vol. 99, no. 0295.

[6] M. Khalili, K. Jadidi, M. Karakouzian and S. Amirkhanian, "Rheological properties of modified crumb rubber asphalt binder and selecting the best modified binder using AHP method," Case Studies in Construction Materials, vol. 11, no. e00276, 2019.

[7] N. S. Mashaan, A. H. Ali, M. R. Karim and M. Abdelaziz, "Effect of blending time and crumb rubber content on properties of crumb rubber modified asphalt binder," International Journal of the Physical Sciences, vol. 6, no. 9, pp. 2189-2193, 2011.

[8] J. Shen, S. Amirkhanian, F. Xiao and B. Tang, "Influence of surface area and size of crumb rubber on high temperature properties of crumb rubber modified binders," Construction and Building Materials, 2008.

[9] H. Wei, X. Bai, G. Qian, F. Wang, Z. Li, J. Jin and Y. Zhang, "Aging Mechanism and Properties of SBS Modified Bitumen under Complex Environmental Conditions," Materials, vol. 12, no. 1189, 2019.

[10] R. Tauste, F. Moreno-Navarro, M. Sol-Sánchez and M. Rubio-Gámez, "Understanding the bitumen ageing phenomenon: A review," Construction and Building Materials, vol. 192, pp. 593-609, 2018.

[11] I. M. Zaidullin, L. M. Petrova, M. R. Yakubov and D. N. Borisov, "Variation of the Composition of Asphaltenes in the Course of Bitumen Aging in the Presence of Antioxidants," Russian Journal of Applied Chemistry,, vol. 86, no. 7, pp. 1070-1075, 2013.

[12] D. Lesueur, "The colloidal structure of bitumen: Consequences on the rheology and on the mechanisms of bitumen modification," Advances in Colloid and Interface Science, vol. 145 , pp. 42-82, 2009.

[13] K. A. Galal, T. D. White and A. J. Hand, "Second Phase Study of Changes in In-Service Asphalt." Volume I: Main ReportJoint Transportation Research program FHWA/IN/JTRP-99/7," June 2000.

[14] A. Papagiannakis and E. Masad, "Asphalt Materials," in Pavement Design and Materials, JohnWiley \& Sons, Inc., 2008, p. 114.

[15] G. D. Airey, "Use of Black Diagrams to Identify Inconsistencies in Rheological Data," Road Materials and Pavement Design, vol. 3, no. 4, pp. 403-424, 2002.

[16] J. Shen and S. Amirkhanian, "The influence of crumb rubber modifier (CRM) microstructures on the high temperature properties of CRM binders," The International Journal of Pavement Engineering, vol. 6, no. 4, pp. 265-271, 2005.

[17] H. Wang, X. Liu, P. Apostolidis, M. v. d. Ven, S. Erkens and A. Skarpas, "Effect of laboratory aging on chemistry and rheology of crumb rubber modified bitumen," Materials and Structures, vol. 53, no. 26, 2020.

[18] S.-C. Huang and A. T. Pauli, "Particle Size Effect of Crumb Rubber on Rheology and Morphology of Asphalt Binders with Long-term Aging," Road Materials and Pavement Design, vol. 9, no. 1, pp. 73-95, 2008.

[19] M. R. Ibrahim, H. Y. Katman, M. R. Karim, S. Koting and N. S.Mashaan, "A Review on the Effect of Crumb Rubber Addition to the Rheology of Crumb Rubber Modified Bitu- 




\begin{tabular}{|c|c|c|c|}
\hline I $G^{*}$ unmodified & $-\left|G^{*}\right|$ LCR $10 \%$ & $\mathbf{\Lambda}\left|G^{*}\right| \operatorname{LCR} 15 \%$ & - |G*| LCR 20\% \\
\hline - RTFO Aged | $\mathrm{G}^{*} \mid$ Unmodified & $\diamond$ RTFO Aged | G*| LCR 10\% & $\Delta$ RTFO Aged | G*| LCR 15\% & ORTFO Aged | $G^{*} \mid$ LCR 20\% \\
\hline In unmodified & ๑ 6 LCR $10 \%$ & \ 6 LCR $15 \%$ & o LCR $20 \%$ \\
\hline RTFO Aged $\delta$ unmodified & • RTFO Aged $\delta$ LCR $10 \%$ & RTFO Aged 5 LCR $15 \%$ & ORTFO Aged 6 LCR $20 \%$ \\
\hline
\end{tabular}

Fig. 15: $\left|\mathrm{G}^{*}\right|$ and $(\delta)$ master curve 60/70 aged and un-aged bitumen

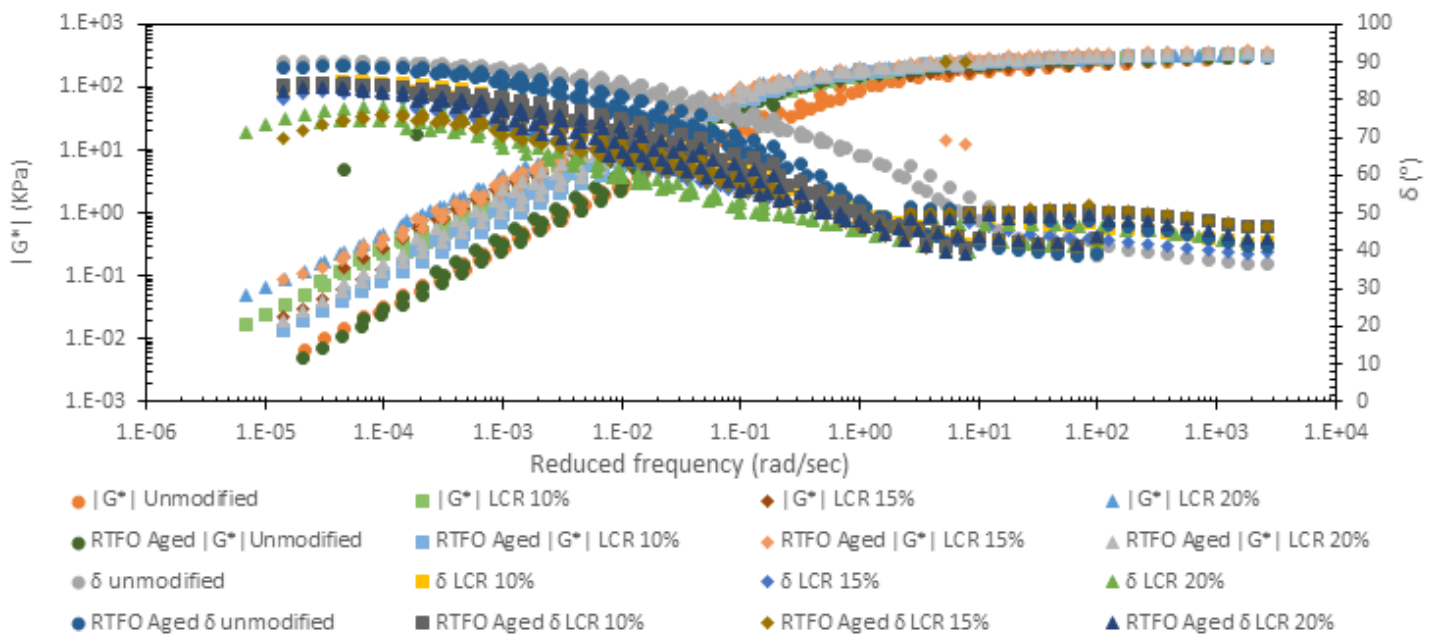

Fig. 16: $\left|\mathrm{G}^{*}\right|$ and $(\delta)$ master curve 80/100 aged and un-aged bitumen

men," Advances in Materials Science and Engineering, vol.

2013, 2013. 